\title{
Performance and Emissions Comparison between Biomethane and Natural Gas Fuel in Passenger Vehicles
}

\author{
Fabio Cignini ${ }^{1, *}$, Antonino Genovese ${ }^{1}$, Fernando Ortenzi ${ }^{1}$, Stefano Valentini ${ }^{2}$, and \\ Alberto Caprioli ${ }^{3}$ \\ ${ }^{1}$ Italian National Agency for New Technologies and Environment (ENEA), Via Anguillarese,301 - \\ 00123 Rome, Italy \\ ${ }^{2}$ Attractiveness Research Territory of Emilia-Romagna region (ART-ER), Via Gobetti, 101 - 40129 \\ Bologna, Italy \\ ${ }^{3}$ IREN S.P.A., Via Nubi di Magellano, 30 - 42123 Reggio Emilia (Italy)
}

\begin{abstract}
Bio-methane as fuel in a natural gas engine is a viable solution to reduce greenhouse gas emissions. The present paper illustrates the results of the first set of measurements carried out in the BiomethER project (EULIFE). BiomethER aimed to design and build two innovative bio-methane production plants, located in Emilia Romagna region (Italy), fed by different feedstock: the first one with sewage sludge and the other with landfill waste. Biogas extracted by the anaerobic digester was cleaned and upgraded to biomethane for road vehicles application. To verify the compatibility of biomethane in conventional compressed natural gas engine (CNG) vehicles, three passenger cars have been tested with two gases: conventional natural gas and bio-methane coming by BiomethER sewage sludge plant. Test concerned dynamic performances and exhaust emissions and was operated on the chassis dynamometer facility, in ENEA Casaccia Research Centre. Preliminary results showed no appreciable deviation was noticeable for fuel consumption and $\mathrm{CO} 2$ emissions between the two fuels, acceleration and maximum power were almost the same for the three vehicles tested. The WTW evaluation of GHG emissions for the biomethane resulted in up to $79 \%$ lower in comparison with natural gas provided by the Italian pipeline.
\end{abstract}

\section{Introduction}

At present days one of the biggest worldwide challenges is the reduction of environmental impact produced by energy-intensive sectors largely depending on fossil fuels. Anthropogenic $\mathrm{CO} 2$ originating from the combustion of carbon-based fuel is considered responsible for climate change along with other gases (methane, fluorinated gases, nitrous oxide). More efforts are underway to contrast the increase of average earth temperature and Conference of Parties (COPs) agreements stated in $2{ }^{\circ} \mathrm{C}$ the "red line" of maximum temperature increase beyond which an irreversible climate change will take place. In later

\footnotetext{
*Corresponding author: author@email.org
} 
years, the European Union (EU) launched several initiatives to contrast climate change and some were addressed to decrease the $\mathrm{CO} 2$ emissions caused by the transport sector. It is recognized that almost a quarter of $\mathrm{CO} 2$ emissions is originated by transport and that it is the main source of air pollution in urban areas. Within the transport sector, road transport is the biggest emitting source accounting for almost three-quarters of GHG emissions. EU strategies for transport decarbonisation includes a large set of measures to support the transition toward green mobility. Among them stand out an acceleration in deployment of low-emissions alternative fuel for transport, such as electricity, hydrogen, advanced biofuels, and spreading of low emissions vehicles. Directive 2014/94 (DAFI) established a set of measures for the deployment of alternative fuels infrastructure to promote the development of a large refuelling network including compressed and liquefied natural gas (CNG and LNG), hydrogen and electric energy.

The Renewable Energy Directive (RED) 2009/28 [1] settled national targets for the share of energy from renewable sources in transport in 2020 and established sustainability criteria for biofuels. Each member State shall ensure a share of renewable energy at least $10 \%$ from transport in 2020. Directive 2009/30 on Fuel Quality Directive (FQD) [2] sets a target for life cycles GHGs emissions reduction and defines the criteria of sustainability for biofuels inherent the GHG reduction, raw material, land use, and biodiversity protection. Finally, Directive 2018/2001 on the promotion of the use of energy from renewable sources (wellknown as RED II) imposed a share of $14 \%$ of renewable energy for the transport sector with a sub-target for advanced biofuels of $3.5 \%$ in 2030 .

The 2030 Climate \& Energy framework includes important targets in the period 2021-2030 in terms of GHG emissions reduction, renewable energy increasing, and improvement in energy efficiency. Member States are invited to adopt national energy and climate plans for the period 2021-2030 to achieve these targets.

Accordingly to Eurostat statistics (updated up to 2018 [3] and [4]), all 2020 targets have been widely achieved and let hope the green revolution could happen. So, the EU raised the bar with $40 \%$ of GHG reduction and $27 \%$ of renewable energy by 2030 [5], with a potential reduction of $80-95 \%$ of GHG and $55-75 \%$ of gross final energy consumption from renewable sources by 2050 [6]. A role in these big challenges can be taken from bio-methane [7]. Biomethane is produced from biogas after a cleaning and upgrading process. There are two primary production pathways for biogas: landfill and anaerobic digestion of biodegradable material. Later, biogas is cleaned from impurities (i.e. ammonia, sulphur, and hydrogen components) and upgraded to biomethane removing $\mathrm{CO} 2$. The current state of the art offers several promising processes to produce biogas throughput anaerobic digestion of organic compounds, from waste and agriculture scraps (as waste treatments, livestock, agricultural process and so on). Several research projects as BiomethER [8], Biosurf [9] and IEAGHG's studies (IEA Greenhouse Gas R\&D) suggest biofuels could save GHG emissions up to $10-13 \%$ of the world's current emissions by 2050 [10].

BiomethER Project, co-founded by EU as part of LIFE programme, aimed to design and build two innovative bio-methane production plants in Emilia Romagna region (Italy), based on sewage sludge fermentation and landfill waste treatment (by separating the organic part of urban garbage) respectively. Specifically, the biogas derived from the sewage sludge plant is filtered and upgraded up to biomethane available for transportation. To replace the fossil methane with bio-methane in a natural gas vehicle (NGV), a comparison was performed to evaluate the energy and environmental performances of three identical vehicles powered by those two fuels.

Tests concern pollutant emissions and fuel consumption at dynamic roller bench on standard driving cycles and, accelerations and maximum power measuring on the chassis dynamometer, conducted mainly at ENEA Casaccia research centre (Fig. 1) in June and July 2019. 


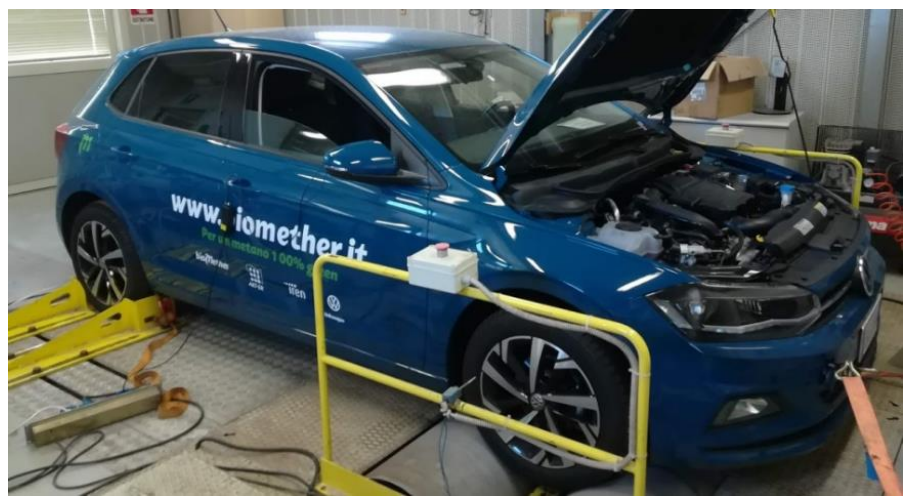

Fig. 1. One of the NGVs tested in the chassis dynamometer of ENEA facility

Being interesting to evaluate a trend in emissions, fuel consumption and dynamic performances at a various grade of engine wear the testing campaign will be repeated when vehicles will have reach 15000 and $30000 \mathrm{~km}$.

This paper reports the results of the first testing campaign, it is organized into four paragraphs: 2 Testing Campaign Description, 3 Well To Wheel GHG Emissions, 4 Results of Testing Campaign and 5 Conclusions.

\section{Testing campaign description}

The target of this experimental campaign is to make a comparison of the environmental and energy performance of NGV passenger cars powered with natural gas and biomethane. Cars under testing were three passenger cars equipped with a CNG engine complying with EURO 6 standard and belonging to the B segment. When tests starting all cars had 1000 kilometres covered (just the minimum required for a break-in).

A car was fuelled with natural gas available at refuelling station near the ENEA Casaccia test facility (Rome) while the other two were powered with biomethane coming from Roncocesi (RE) biomethane production plant.

The measurement concerns fuel consumption, emissions, and dynamic performances. All of them have been collected during the following tests on the dynamometer chassis: Driving cycle, Maximum acceleration, Maximum power. These procedures measure if there are any changes of performances during a common dynamic usage of vehicle, which stresses all parts (intake air pipes, valves, exhaust pipes, etc...) and all their mechanical and electrical settings. In this case, if there were an unwanted behaviour due to fuel characteristics or combustion process it would be also an evident power loss (in comparison with fuel approved).

The comparison of maximum power curves between two fuels highlights any differences in performance, such comparison becomes more important with the increase of engine wear. Main exhaust gas emissions, carbon dioxide (CO2), carbon monoxide (CO), nitrogen oxide (NOx) and hydrocarbons (HC), were collected by a Portable Emissions Measurement System (PEMS). Such system measured also the exhaust airflow (through a Pitot pipe and a Lambda probe), allowing an evaluation of the air/fuel rate and fuel consumption. In order to validate results obtained, it was compared the fuel consumption measure by PEMS with the one obtained from engine data, and provided by the manufacturer through On-Board Diagnostic (OBD) connection. Main data of vehicles are listed in Table 1. 
Table 1. Nominal specification of test vehicle (OEM data).

\begin{tabular}{|c|c|}
\hline Parameter & Description or value \\
\hline Vehicle Type / Category / Year & $1000 \mathrm{~km}$ \\
\hline Odometer reading & $1185 \mathrm{~kg}$ \\
\hline Inertia Class & Petrol and Methane \\
\hline Fuel & Euro 6C + Euro 6D TEMP \\
\hline Emission standard & $89 \mathrm{~g} / \mathrm{km}$ \\
\hline CO2 emissions (NEDC cycle) & $360 \mathrm{~km}$ (methane) $+800 \mathrm{~km}$ (petrol) \\
\hline Range & MPI / Turbocharged \\
\hline Tank capacity & Homogeneous stoichiometric \\
\hline Injection System / Aspiration & Three-Way Catalyst \\
\hline Combustion Type & $999 \mathrm{~cm}^{3} / 3$ \\
\hline After-treatment device & $66 \mathrm{KW} \mathrm{(between} 4500-5800 \mathrm{RPM}) /$ \\
\hline Displacement / Number cylinder & $160 \mathrm{Nm}(1900 \mathrm{RPM})$ \\
\hline Max. Power / Max. Torque & \\
\hline
\end{tabular}

The vehicle year of approval is 2017 , the registration date is 2018 , so, they must comply with emissions tests with the NEDC driving cycle. In the present study, the authors choose to test also the newest WLTC driving cycle. In fact, from the 1st of September 2019, all the light-duty vehicles that are to be registered in the EU must comply with the WLTP standards.

The WLTP replaces the NEDC as European homologation test bench procedure. Perform a driving cycle on a dynamometer chassis allows a comparison avoiding all the variables of real driving: traffic jams, lights, weather conditions, driving style, and so on. In this research both NEDC and WLTC driving cycles have been tested, each one repeated at least three times. To perform a test at dynamometer test bench we need to know some vehicle powertrain specification as gear ratios, maximum power, weight, RPM working range of the engine; values of those parameters are described in Table 2.

The WLTC cycle lasts about 1800 seconds and the vehicle travel for $28.9 \mathrm{~km}$ with an average speed of $58 \mathrm{~km} / \mathrm{h}$. The acceleration test simulates the overtaking manoeuvres of vehicles in a real situation, starting at different speeds. In this case, the vehicle starts from 0 to $100 \mathrm{~km} / \mathrm{h}$ and from 40 to $100 \mathrm{~km} / \mathrm{h}$.

Table 2. Nominal specification of vehicle powertrain.

\begin{tabular}{|c|c|c|c|c|c|c|c|c|}
\hline $\begin{array}{c}\text { Max } \\
\text { power }\end{array}$ & $\begin{array}{c}\text { Kerb } \\
\text { mass }\end{array}$ & $\begin{array}{c}\text { Max } \\
\text { Rpm }\end{array}$ & $\begin{array}{c}\text { Idling } \\
\text { speed }\end{array}$ & \multicolumn{4}{|c|}{ Engine RPM - Vehicle speed (NV) ratio } \\
\hline$(\mathrm{kW})$ & $(\mathrm{kg})$ & $(\mathrm{rpm})$ & $(\mathrm{rpm})$ & $1 \mathrm{st}$ & $2 \mathrm{nd}$ & $3 \mathrm{rd}$ & 4 th & 5 th \\
\hline 67 & 1348 & 5500 & 950 & 126.53 & 65.63 & 43 & 29.58 & 22.59 \\
\hline
\end{tabular}

The first part of acceleration test measures how long it takes to reach $100 \mathrm{~km} / \mathrm{h}$ with a standing start, increasing the gear one by one. The second part concerns to engage the highest gear and decelerate vehicle speed under $40 \mathrm{~km} / \mathrm{h}$ by using the cut off (both accelerator and brake pedals are in the full up position), immediately under $40 \mathrm{~km} / \mathrm{h}$ the accelerator pedal goes in kick down, requiring maximum power to the engine.

The test ends when speed reaches $100 \mathrm{~km} / \mathrm{h}$. Test at maximum power aims to measure power up to the wheels, by using the dynamometer chassis with a standing start up to maximum speed, with proper gear shifting. It is analogue to maximum acceleration but the test ends when the vehicle reaches its maximum speed. 


\section{Well To Wheel GHG Emissions}

Present analysis takes care of equivalent GHG emissions from the production/extraction of fuel up to its consumption in the NGV. Each fuel production chain is characterized by its GHG emissions [1] produced in three separated phases: raw material extraction (cultivation in case of biomass) and upgrading to become an energy carrier; transport and distribution up to the final customer; conversion from chemical energy to mechanical energy.

These three phases identify respectively three nodes of fuel chain that can be used to separate the emissions evaluation: well, tank and wheel. So, total GHG emissions can be analysed between those three nodes with the two steps of well to tank (WTT) and tank to wheel (TTW). The sum of the two contributions is the total GHG from well to wheel.

In the following are described those two steps for both fuels (biomethane and methane), then, a comparison of both WTW GHG emissions.

\subsection{Natural gas}

The study proposed by JR-EUCAR-CONCAWE [11] shows the natural gas plants all whole Europe and their $\mathrm{CO} 2$ emissions due to extraction plants and transport through pipelines and Liquid Natural Gas (LNG) ships, also called methane tankers. These measurements include liquefying, filtering, and pressurizing treatments required to serve local storage and gas stations. The Italian Natural Gas (NG) extraction plants are in the Adriatic Sea and Italian southern regions, but they are not enough for Italian needs, so, Italy imports natural gas through pipelines from other countries: northern Europe (Russia, Netherland, Norway), Africa (Algeria, Libya and so on); at the same time it imports also Liquified Natural Gas (LNG) regasified from Niger, Mozambique, Indonesia, Malaysia, and Algeria.

Such variety of gases implies differences of chemical composition, methane number, calorific value and Wobbe index (IW); see [12] for more details.

The present study adopts the Italian average of net calorific value (NCV), referred to 2017 data, it values 35.27 MJ/Nm3, while the European average values 35.7 MJ/Nm3. Emission factor value of $\mathrm{CO} 2$ equivalent for $\mathrm{NG} \mathrm{EU} \mathrm{mix} \mathrm{is} \mathrm{equal} \mathrm{to} 13 \mathrm{gCO} 2 \mathrm{eq} / \mathrm{MJf}$. So, equation 1 allows calculating the total greenhouse gas emissions expressed as equivalent carbon dioxide per kilometre GHGWTTkm.

$$
\mathrm{GHG}_{\mathrm{WTT}} \mathrm{km}\left[\frac{\mathrm{gCO}_{\mathrm{eq}}}{\mathrm{km}}\right]=\frac{\mathrm{C}_{\mathrm{f}}}{\mathrm{M}_{\mathrm{v}}} \cdot \mathrm{PCI} \cdot \mathrm{GHG}_{\mathrm{WTT}}
$$

The average consumption cf equal to $30 \mathrm{~g} / \mathrm{km}$ has been measured during the driving cycle on chassis dynamometer (see chapter "5 Results of testing campaign" in the following), fuel density $M_{v}$ values $0.736 \mathrm{~kg} / \mathrm{Nm} 3$, net calorific value $(\mathrm{PCI})$ is $35.27 \mathrm{MJ} / \mathrm{Nm} 3, G H G_{W T T}$ is $13.00 \mathrm{gCO} 2 \mathrm{eq} / \mathrm{MJf}$, so, the results of equation 1 is $18.69 \mathrm{gCO} 2 / \mathrm{km}$.

The second part of the evaluation concerns emissions from TTW, it includes direct carbon dioxide due to combustion and to indirect emissions of unburned gases (i.e. hydrocarbons). The emission factors (IPCC) of equivalent carbon dioxide are shown in Table 3.

Table 3. Equivalent emission factors of green-house gases (IPCC).

\begin{tabular}{|c|c|}
\hline Gas & IPCC $[\mathbf{t C O 2 e q} / \mathbf{t}]$ \\
\hline $\mathrm{CO} 2$ & 1 \\
\hline $\mathrm{CH} 4$ (and $\mathrm{HC})$ & 25 \\
\hline $\mathrm{N} 2 \mathrm{O}$ & 298 \\
\hline
\end{tabular}


Equation 2 allows to calculate the GHG emissions, they are expressed as equivalent carbon dioxide per kilometre GHGTTWkm from TTW. The emissions of carbon dioxide (ECO2) is $82.24 \mathrm{gCO} 2 / \mathrm{km}$, hydrocarbons (EHC) is $0.046 \mathrm{~g} / \mathrm{km}$, those two pollutants are measured within the WLTC driving cycle [13] on the chassis dynamometer. While, the nitrous oxide emission (EN2O) is not measured directly from exhaust gas but calculated adopting the EMEP/EEA emission factor equal to $0.001 \mathrm{~g} / \mathrm{km}$ (tier 2 method, [14]). So, the result of equation 2 is $83.7 \mathrm{gCO} 2 \mathrm{eq} / \mathrm{km}$.

$$
\mathrm{GHG}_{\mathrm{TTW}} \mathrm{km}\left[\frac{\mathrm{gCO} 2 \mathrm{eq}}{\mathrm{km}}\right]=\mathrm{IPCC}_{\mathrm{CO} 2} \cdot \mathrm{E}_{\mathrm{CO} 2}+\mathrm{IPCC}_{\mathrm{HC}} \cdot \mathrm{E}_{\mathrm{HC}}+\mathrm{IPCC}_{\mathrm{N} 2 \mathrm{O}} \cdot \mathrm{E}_{\mathrm{N} 2 \mathrm{O}}
$$

\subsection{Biomethane}

Italian regulations for biomethane fuel comply with a chemical composition of $97.3 \%$ of pure methane $(\mathrm{CH} 4)$ and maximum residue in nitrogen, carbon dioxide and hydrogen of $2.2 \%$, $0.02 \%$ and $0.025 \%$ respectively.

Table 4 shows the physical and chemical parameters of biomethane used by the BiomethER project, it has a gross calorific value (GCV) and an IW lower than Italian average values, respectively of $3 \mathrm{MJ} / \mathrm{m} 3$ and $2 \mathrm{MJ} / \mathrm{m} 3$. The methane number $(\mathrm{MN})$ of BiomethER is close to pure methane $(\mathrm{NM}=100)$ while methane of Italian pipeline has an $\mathrm{MN}$ that ranges from 75 to 98 depending on sampling location. So, this new methane is suitable to replace natural gas in an internal combustion engine.

For biomethane produced from sewage sludge, the related tailpipe $\mathrm{CO} 2$ emissions are treated as biogenic and not considered to contribute as GHG. So, WTT CO2 emissions are equal to zero. The GHG emissions per unit of fuel values $14.8 \mathrm{gCO} 2 \mathrm{eq} / \mathrm{MJf}$ [12], the carbon dioxide per unit of kilometre values $20.53 \mathrm{gCO} 2 \mathrm{eq} / \mathrm{km}$. This value does not include the additional $\mathrm{HC}$ and $\mathrm{N} 2 \mathrm{O}$ produced during combustion within the engine, that can be evaluated as $1.38 \mathrm{gCO} 2 \mathrm{eq} / \mathrm{km}$, so, the GHG from TTW for biomethane values $21.53 \mathrm{gCO} 2 \mathrm{eq} / \mathrm{km}$.

Table 4. Physical and chemical parameters of biomethane used by BiomethER.

\begin{tabular}{|c|c|c|c|}
\hline Parameter & Unit & $\begin{array}{c}\text { Biomethane } \\
\text { (BiomethER project) }\end{array}$ & $\begin{array}{c}\text { Methane } \\
\text { (Average of Italian pipeline) }\end{array}$ \\
\hline Gross calorific value (GCV) & $\mathrm{MJ} / \mathrm{m} 3$ & 36.76 & 39.11 \\
\hline Net calorific value $(\mathrm{NCV})$ & $\mathrm{MJ} / \mathrm{m} 3$ & 33.09 & 35.31 \\
\hline Wobbe index (IW) & $\mathrm{MJ} / \mathrm{m} 3$ & 48.80 & 50.65 \\
\hline Density & $\mathrm{kg} / \mathrm{m} 3$ & 0.729 & 0.733 \\
\hline Relative density & & 0.567 & 0.598 \\
\hline Molecular weight & $\mathrm{mg} / \mathrm{mol}$ & 16.34 & 16.86 \\
\hline Methane number $(\mathrm{MN})$ & & 99.09 & From 75 to 98 \\
\hline
\end{tabular}

\subsection{Well To Wheel GHG Comparison}

Total greenhouse gases from well to wheel GHGWTWkm can be obtained by the sum of previous two evaluations: from well to tank GHGWTTkm and from tank to wheel GHGTTWkm.

Table 5 summarizes the comparison of results, it highlights that biomethane cycle life outputs $79 \%$ less GHG than traditional methane. The testing campaign was conducted in ENEA research centre of Casaccia, the acquisition instrumentation included: the chassis dynamometer (made by Assing), the Horiba OBS1300 (PEMS), and an OBD diagnostic 
software made by ENEA researcher to collect engine data through Original Equipment Manufacturer (OEM) sensors.

Table 5. Comparison of greenhouse gas emission from well to wheel for both fuels analysed, values are in $\mathrm{gCO} 2 \mathrm{eq} / \mathrm{km}$.

\begin{tabular}{|c|c|c|}
\hline Parameter & Biomethane & Methane \\
\hline Well to tank (WTT) & 0.00 & 18.69 \\
\hline Tank to wheel (TTW) & 21.45 & 83.70 \\
\hline Total GHG emission & 21.45 & 102.40 \\
\hline
\end{tabular}

\section{Results of testing campaign}

Fig. 2 shows the cumulative trends of main pollutants during a WLTC driving cycle. They rise greater when there is a deep acceleration with high loads requested to the engine, e.g. the NOx between 1100 and 1200 seconds has a rapid growth. The carbon monoxide has the highest growth between 1400 and 1800 seconds; when the speed rises over $100 \mathrm{~km} / \mathrm{h}$ and the power is closest to the maximum available.

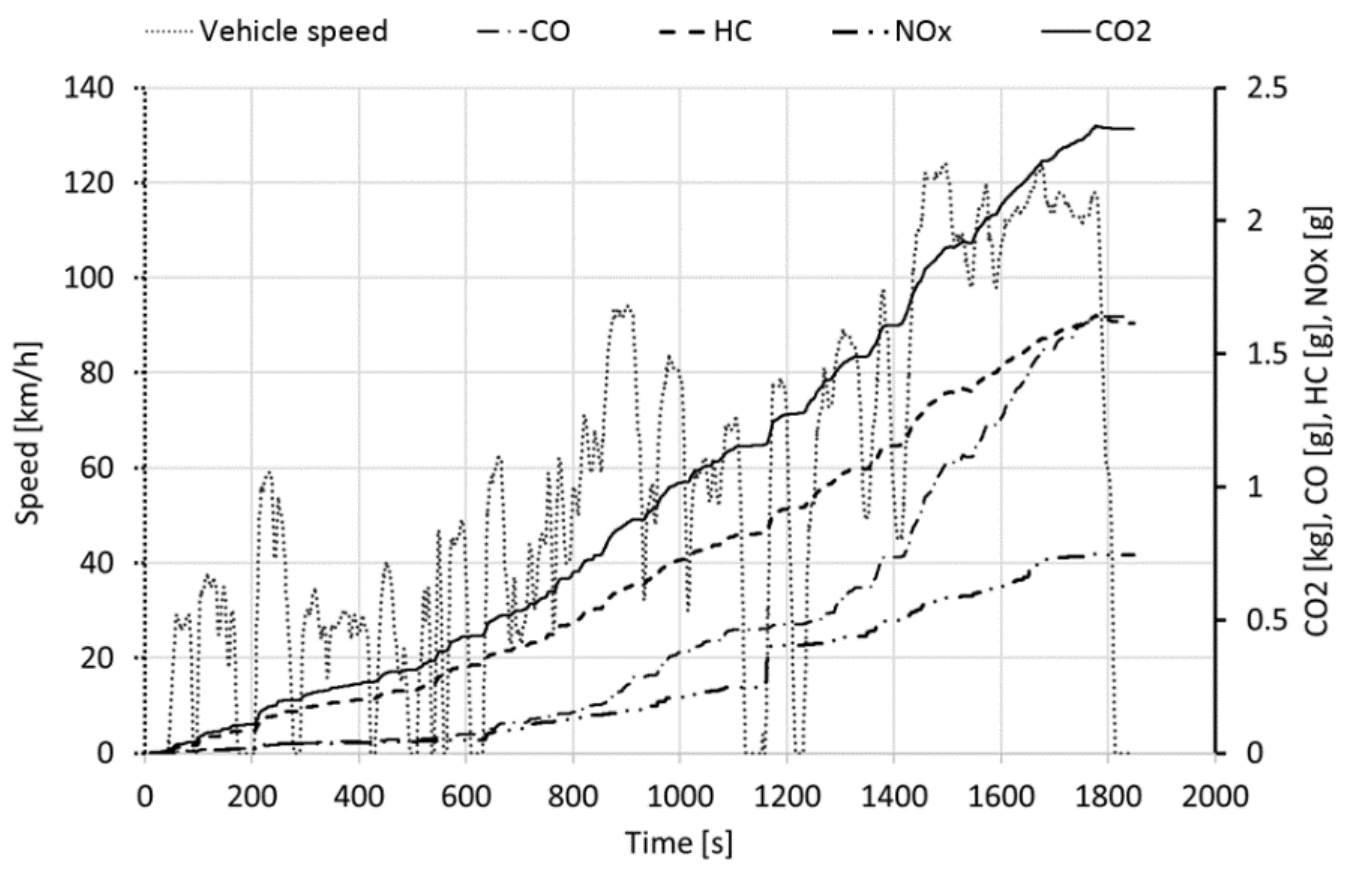

Fig. 2. Cumulative curves of pollutant during a WLTC driving cycle.

Fig. 3 shows the fuel consumption and the carbon dioxide emissions for the three vehicles tested, where vehicle number 3 is the one powered by traditional methane. The three vehicles consume between 30 and $31 \mathrm{~g} / \mathrm{km}$ of fuel. The carbon dioxide emissions are between 79 and $87 \mathrm{~g} / \mathrm{km}$, they comply with the next EU regulations that prescribe $95 \mathrm{~g} / \mathrm{km}$ as limit by January the 1 st of 2020, then postponed to January 1st of 2021 [1]. 


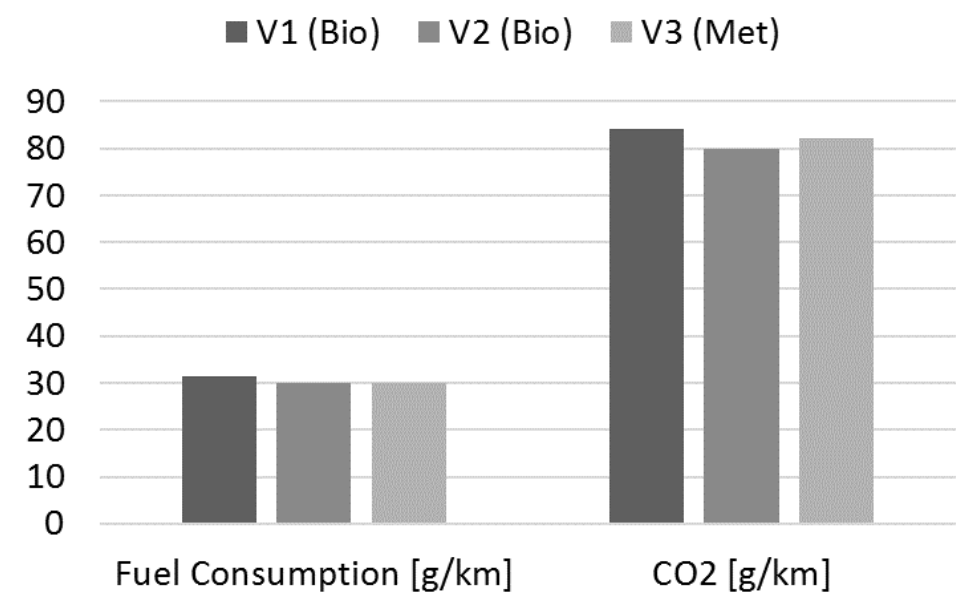

Fig. 3. Comparison of fuel consumption and $\mathrm{CO} 2$ emissions during a WLTC driving cycle.

Fig. 4 confirms that vehicle tested have all emissions under the regulatory limits independently by fuel, they are indicated in the same figure with dotted lines $(1 \mathrm{~g} / \mathrm{km}$ of CO, $0.06 \mathrm{~g} / \mathrm{km}$ of NOx, and $0.1 \mathrm{~g} / \mathrm{km}$ of $\mathrm{HC}$ ). Hence, both biomethane powered vehicles (V1 and V2) emits 33\% NOx lesser than the traditional methane, while $\mathrm{HC}$ and $\mathrm{CO}$ have not enough differences.

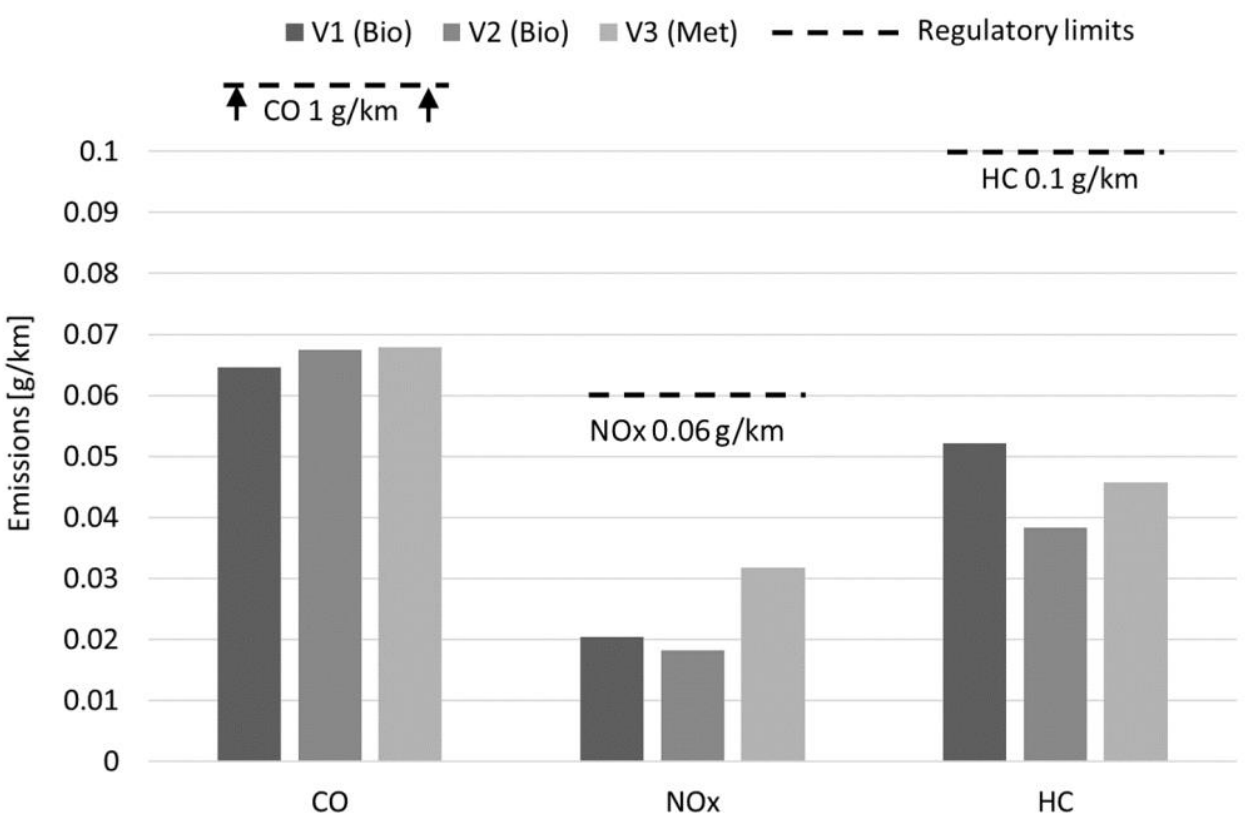

Fig. 4. Pollutants measurements during a WLTC driving cycle. 
Table 6 summarizes results achieved during the WLTC and NEDC driving cycles seen in Fig. 3 and Fig. 4. The NEDC test on V2 is not available due to technical reasons.

Table 6. Results of measurements during NEDC and WLTC driving cycles.

\begin{tabular}{|c|c|c|c|c|c|c|c|}
\hline \multicolumn{2}{|c|}{} & Distance & $\begin{array}{c}\text { Fuel } \\
\text { consumption }\end{array}$ & CO2 & CO & NOx & HC \\
\hline Vehicle & $\begin{array}{c}\text { Driving } \\
\text { cycle }\end{array}$ & $\mathrm{km}$ & $\mathrm{g} / \mathrm{km}$ & $\mathrm{g} / \mathrm{km}$ & $\mathrm{g} / \mathrm{km}$ & $\mathrm{g} / \mathrm{km}$ & $\mathrm{g} / \mathrm{km}$ \\
\hline $\begin{array}{c}\text { V1 } \\
\text { (Biomethane) }\end{array}$ & NEDC & 11.0 & 32.462 & 87.649 & 0.040 & 0.033 & 0.062 \\
\cline { 2 - 8 } & WLTC & 28.9 & 31.302 & 84.265 & 0.065 & 0.020 & 0.052 \\
\hline $\begin{array}{c}\text { V2 } \\
\text { (Biomethane) }\end{array}$ & WLTC & 28.9 & 29.954 & 79.868 & 0.067 & 0.018 & 0.038 \\
\hline \multirow{2}{*}{ V3 (Methane) } & NEDC & 11.0 & 32.227 & 88.423 & 0.049 & 0.059 & 0.063 \\
\cline { 2 - 8 } & WLTC & 28.9 & 30.059 & 82.243 & 0.068 & 0.032 & 0.046 \\
\hline
\end{tabular}

Table 7 summarizes results of acceleration tests. Each test has been repeated several times to improve driver skills (shifting timing and vehicle behaviour). So, Table 7 shows the better results achieved, represented by the lowest time for each test.

Table 7. Results of acceleration tests in seconds.

\begin{tabular}{|c|c|c|}
\hline Vehicle & $\mathbf{4 0 - 1 1 0 ~} \mathbf{~ k m} / \mathbf{h}$ & $\mathbf{0 - 1 0 0} \mathbf{~ k m} / \mathbf{h}$ \\
\hline V1 (Biomethane) & 23.7 & 12.4 \\
\hline V2 (Biomethane) & 23.8 & 13.7 \\
\hline V3 (Methane) & 23.4 & 13.0 \\
\hline
\end{tabular}

Fig. 5 shows the results of maximum power tests, each vehicle repeats two times the test. The maximum power is greater than or equal to the vehicle manufacturer's declaration (67 $\mathrm{kW}$ ), for V1 and V2 (the biomethane vehicles) is between 67 and $69.5 \mathrm{~kW}$, and the torque is between 150 and $165 \mathrm{Nm}$. Thus, the power of V3 is between 69 and $71 \mathrm{~kW}$ and the torque is between 169 and $173 \mathrm{Nm}$. The results show power and torque losses, respectively of $2.9 \%$ and $7.5 \%$ by biomethane vehicles in comparison with traditional methane. Such differences belong to sensors tolerance fields and not directly connected to the fuels. 


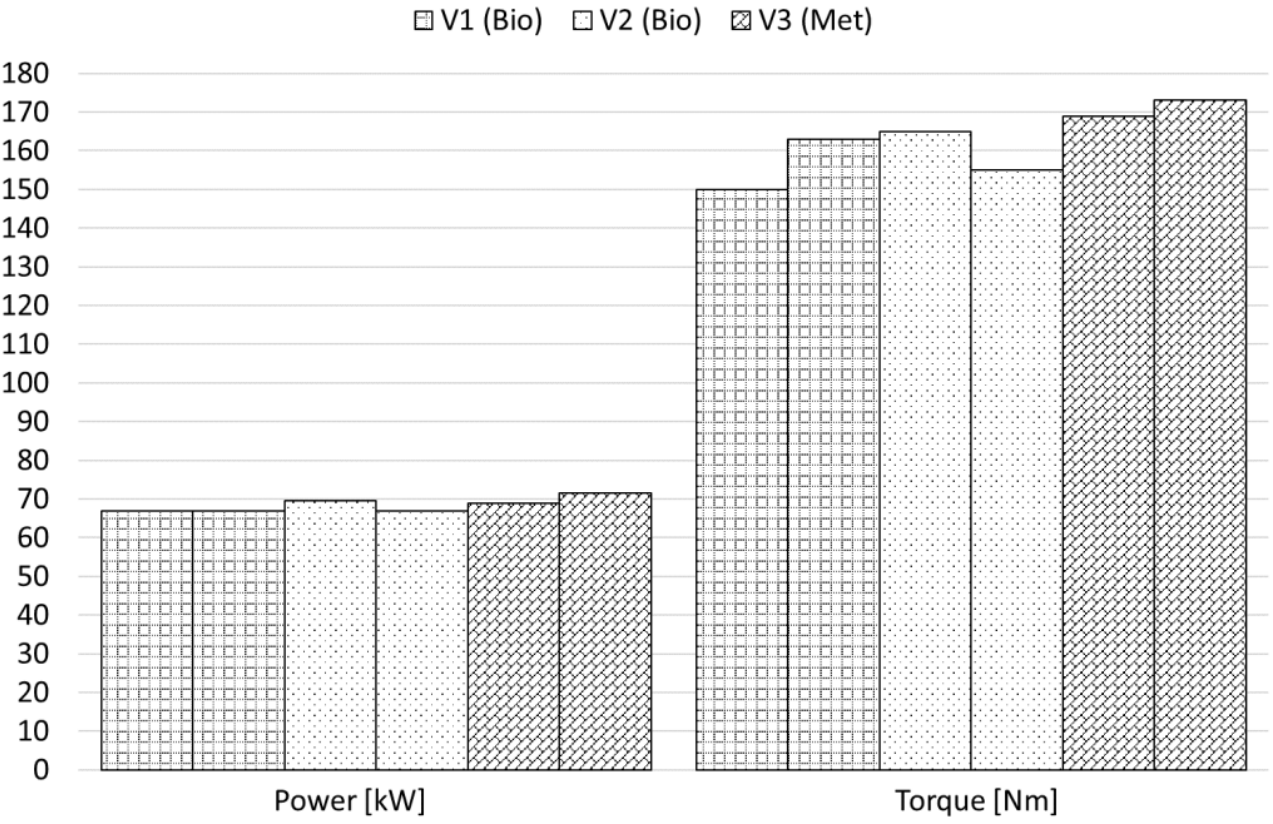

Fig. 5. Power and Torque comparison.

Fig. 6 shows the power trends related to the engine revolution (RPM), only one measurement for each vehicle has been shown. There is a little power loss for V1 when the engine RPM is between 3500 and 5000. The tests of V1 show a power loss between 4000 and 5000 RPM, it has also a large gap in comparison with V2. The V2 is close to V3. The large gap between the two curves V2 and V3 is attributable to a driver error during a gear shift. The maximum power test is done manually at roller bench, the driver should release the accelerator pedal and press clutch pedal in the right time with same engine RPM for all the tests, maybe V3 curve has a non-perfect timing during a shift (e.g. between third and fourth gear) so the engine can't express maximum power as the other tests. 


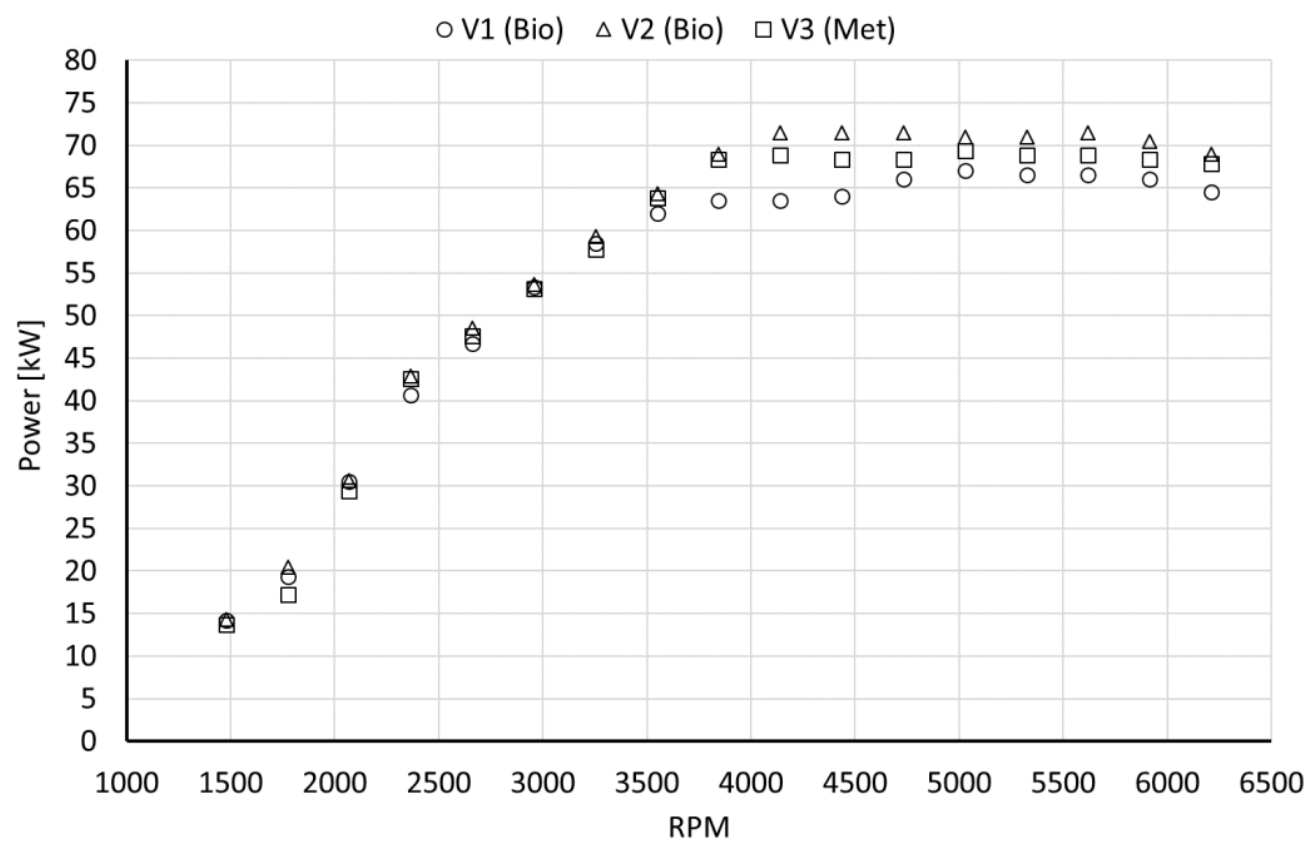

Fig. 6. Power versus RPM trend.

\section{Conclusions}

The present paper describes an experimental campaign of project BiomethER, where a biomethane fuel replaces the traditional (non-renewable) methane in a natural gas vehicle (NGV). This is the first of three campaigns within the project, vehicles tested have less than $15000 \mathrm{~km}$ each. The other two campaigns are foreseen when the vehicle odometers will reach $15000 \mathrm{~km}$ and $30000 \mathrm{~km}$.

Three vehicles have been tested by measuring fuel consumption, emissions, and dynamic performances. Two vehicles are powered by biomethane and the other one by traditional methane. Moreover, it has been evaluated the equivalent carbon dioxide emission per kilometre from well to tank and from tank to wheel. The comparison highlights that biomethane cycle life from well to wheel outputs $79 \%$ less GHG than traditional methane ( $21 \mathrm{gCO} 2 \mathrm{eq} / \mathrm{km}$ of biomethane against $102 \mathrm{gCO} 2 \mathrm{eq} / \mathrm{km}$ of methane). Such difference is due to less emission in the well to tank path.

The tests have been conducted to research centre ENEA by using a chassis dynamometer, a PEMS and an OBD diagnostic measurement system.

Results of emissions measurements are:

- Fuel consumption and Carbon dioxide are equal for all vehicles, they need an equal amount of gas to fulfil the WLTC or NEDC driving cycles.

- The amount of CO2 is just under $95 \mathrm{~g} / \mathrm{km}$, so, it complies with the future EU limits by January 2021.

- The CO and HC pollutant emissions are not affected by fuel.

- The biomethane vehicles emit 33\% less NOx than the other powered by methane.

- All vehicles emit pollutants under regulatory limits as manufacturer's declaration. 
Dynamic performance comparison shows:

- Time of acceleration from 0 to $100 \mathrm{~km} / \mathrm{h}$ and from 40 to $100 \mathrm{~km} / \mathrm{h}$ are not affected by fuel.

- All vehicles have a maximum power greater than or equal to $67 \mathrm{~kW}$ (as declared by manufacturer).

- The torque varies between three vehicles with a maximum value of $14 \%$ from the smallest to the largest, equal to $25 \mathrm{Nm}$ in comparison with $175 \mathrm{Nm}$ of maximum torque for V3).

- All vehicles have a comparable power curve within the engine working range (RPM)

The small differences just explained can be attributed to external variables that are not be evaluated, e.g. sensors tolerances or environmental temperature (some tests were done in the morning and some others in the afternoon).

Project BiomethER "Biomethane Emilia-Romagna regional system" was co-financed by the EU LIFE program and the Emilia-Romagna Region LIFE12 ENV/IT/308. We would like to also thank the colleagues of project partners IREN Smart Solutions, Attractiveness Research Territory of EmiliaRomagna region (ART-ER), and Volkswagen Group Italia S.p.A. (VGI) for their comments that greatly improved the manuscript.

\section{References}

1. Official Journal of the European Union, «directive 2009/28/EC of the European Parliament and the council,» (23 April 2009). [Online]. Available: http://www.nezeh.eu/assets/media/fckuploads/file/Legislation/RED_23April2009.pdf. [Accessed on 20 January 2020].

2. Official Journal of the European Union, «directive 2009/30/EC of the European Parliament and the council,» (23 April 2009). [Online]. Available: https://eurlex.europa.eu/lexuriserv/lexuriserv.do?Uri=OJ:L:2009:140:0088:0113:EN:PDF. [Accessed on 20 January 2020].

3. Eurostat, «Energy from renewable sources,» [Online]. Available: https://ec.europa.eu/eurostat/web/energy/data/shares. [Accessed on 20 January 2020].

4. Eurostat, «Energy, transport and environment indicators,» (2018).

5. European Commission, «A policy framework for climate and energy in the period from 2020 to 2030,» 22 January 2014. [Online]. Available: https://eur-lex.europa.eu/legalcontent/EN/TXT/?uri=COM\%3A2014\%3A15\%3AFIN. [Accessed on 21 January 2020].

6. European Commission, «A Roadmap for moving to a competitive low carbon economy in 2050,» (8 March 2011). [Online]. Available: http://www.europarl.europa.eu/meetdocs/2009_2014/documents/com/com_com(2011) 0112_/com_com(2011)0112_en.pdf. [Accessed on 22 January 2020].

7. E. Ryckeboscha, M. Drouillon, and H. Vervaeren, «Techniques for transformation of biogas to biomethane,» Biomass and bioenergy, vol. 35, pp. 1633-1645 (2011).

8. BiomethER project, «Chi siamo,» (2012). [Online]. Available: http://www.biomether.it/p/chi-siamo.html. [Accessed on 22 January 2020].

9. Biosurf project, «About Biosurf,» (2016). [Online]. Available: http://www.biosurf.eu/en_GB/about-biosurf/. [Accessed on 21 January 2020].

10. IEAGHG, «WHO ARE IEAGHG,» [Online]. Available: https://ieaghg.org/aboutus/what-do-we-do. [Accessed on 22 January 2020]. 
11. European Biogas Association, «EBA Annual Report 2019,» (2019). [Online]. Available: https://www.europeanbiogas.eu/wp-content/uploads/2020/01/EBA-AR-2019-digitalversion.pdf. [Accessed on 23 February 2020].

12. L. Beibei, W. Qi, Z. Bing, and B. Jun, «Life cycle GHG emissions of sewage sludge treatment and disposal options in Tai Lake Watershed, China,» Science of The Total Environment, vol. 447, pp. 361-369, (2013).

13. Y. Xiyue, M. Hailin, Z. Heran, X. Zhaoquan and L. Nan, «Environmental impact and economic benefit evaluation of sewage sludge treatment technologies,» (IOP Conference Series: Earth and Environmental Science, 2020).

14. Joint Research Centre of the European Commission, «Well-to-wheels analysis of future automotive fuels and powertrains in the European context,» Publications Office of the European Union, Luxembourg, (2014).

15. SNAM rete gas, «Gas tipici immessi in rete anno termico 2017-2018,» (14 November 2019).

[Online]. Available: http://misura.snam.it/portmis/coortecDocumentoController.do? menuSelected $=4300$. [Accessed on 10 February 2020]. 